\title{
Selection of optimal molecular targets for tumor-specific imaging in pancreatic ductal adenocarcinoma
}

\author{
Willemieke S. Tummers ${ }^{1}$, Arantza Farina-Sarasqueta ${ }^{2}$, Martin C. Boonstra ${ }^{1}$, \\ Hendrica A. Prevoo ${ }^{1}$, Cornelis F. Sier ${ }^{1}$, Jan S. Mieog ${ }^{1}$, Johannes Morreau ${ }^{2}$, Casper H. \\ van Eijck $^{3}$, Peter J. Kuppen ${ }^{1}$, Cornelis J. van de Velde ${ }^{1}$, Bert A. Bonsing ${ }^{1}$, Alexander \\ L. Vahrmeijer ${ }^{1}$ and Rutger-Jan Swijnenburg ${ }^{1}$ \\ ${ }^{1}$ Department of Surgery, Leiden University Medical Center, Leiden, The Netherlands \\ ${ }^{2}$ Department of Pathology, Leiden University Medical Center, Leiden, The Netherlands \\ ${ }^{3}$ Department of Surgery, Erasmus Medical Center, Rotterdam, The Netherlands \\ Correspondence to: Rutger-Jan Swijnenburg, email: r.j.swijnenburg@lumc.nl \\ Keywords: molecular imaging, pancreatic cancer, biomarker \\ Received: January 21, $2017 \quad$ Accepted: May 01, $2017 \quad$ Published: May 26, 2017 \\ Copyright: Tummers et al. This is an open-access article distributed under the terms of the Creative Commons Attribution License 3.0 \\ (CC BY 3.0), which permits unrestricted use, distribution, and reproduction in any medium, provided the original author and source \\ are credited.
}

\section{ABSTRACT}

Discrimination of pancreatic ductal adenocarcinoma (PDAC) from chronic pancreatitis (CP) or peritumoral inflammation is challenging, both at preoperative imaging and during surgery, but it is crucial for proper therapy selection. Tumor-specific molecular imaging aims to enhance this discrimination and to help select and stratify patients for resection. We evaluated various biomarkers for the specific identification of PDAC and associated lymph node metastases. Using immunohistochemistry (IHC), expression levels and patterns were investigated of integrin av $\beta 6$, carcinoembryonic antigen-related cell adhesion molecule 5 (CEACAM5), Cathepsin E (Cath E), epidermal growth factor receptor (EGFR), hepatocyte growth factor receptor (c-MET), thymocyte differentiation antigen 1 (Thy1), and urokinase-type plasminogen activator receptor (UPAR). In a first cohort, multiple types of pancreatic tissue were evaluated $(n=62)$; normal pancreatic tissue $(n=8)$, CP $(n=7)$, PDAC $(n=9)$, tumor associated lymph nodes $(n=32)$, and PDAC after neoadjuvant radiochemotherapy $(n=6)$. In a second cohort, tissues were investigated $(n=55)$ with IHC and immunofluorescence (IF) for concordance of biomarker expression in all tissue types, obtained from an individual patient. Integrin av $\beta 6$ and CEACAM5 showed significantly higher expression levels in PDAC versus normal pancreatic tissue $(P=0.001$ and $P<0.001$, respectively) and $C P(P=0.003$ and $P<0.001$, respectively). Av $\beta 6$ and CEACAM5 expression identified tumor-positive lymph nodes correctly in $84 \%$ and $68 \%$, respectively, and in $100 \%$ of tumor-negative nodes for both biomarkers. In conclusion, av $\beta 6$ and CEACAM5 are excellent biomarkers to differentiate PDAC from surrounding tissue and to identify lymph node metastases. Individually or combined, these biomarkers are promising targets for tumor-specific molecular imaging of PDAC.

\section{INTRODUCTION}

Pancreatic ductal adenocarcinoma (PDAC) is predicted to become the second cause of cancer-related death in 2030 [1]. Patients with PDAC have a dismal prognosis, with a five-year survival rate of less than $5 \%$ [2]. At this point, complete surgical resection is the only potential curative treatment. However, at the time of primary diagnosis, $75 \%$ to $85 \%$ of patients has advanced unresectable disease due to locoregional spread and metastasis [3, 4]. Therefore, accurate identification of potential candidates for resection is crucial to prevent unnecessary surgical risks and delay in systemic therapy [5]. Another challenge during surgery, is that despite 
careful selection of resectable patients using $\mathrm{CT}$, MRI and/or PET imaging, incomplete (R1) resection occurs in up to $70 \%$ of cases [6]. Failure to identify tumor-positive margins during surgery is not surprising, and is due to the tumor's characteristic to quickly spread beyond the pancreas via perineural and perivascular pathways [7] and the inability of the surgeon to differentiate between tumor and (peritumoral) inflammatory pancreatic tissue $[8,9]$. This is also challenging in pre-operative imaging with conventional technique since both PDAC and chronic pancreatitis (CP) may present similar due to abundant stroma.

To improve surgical outcomes, novel neoadjuvant treatment protocols, such as FOLFIRINOX, are being successfully implied in the treatment of PDAC. Unfortunately, a drawback of these neoadjuvant therapies is that current imaging modalities are unable to differentiate between vital tumor and radiochemotherapyinduced tumor necrosis and fibrosis [10-12]. In addition, neoadjuvant treatment effects worsen the ability of the surgeon to differentiate (vital) tumor from fibrotic pancreatic tissue and often times, serial frozen section analysis is required to assess whether to continue a resection.

Tumor imaging using molecularly targeted probes has the potential to play an important role in improving patient management and treatment in these situations. This technique can be used for tumor detection, characterization, staging, and response assessment to neoadjuvant treatment. Moreover, it can facilitate imageguided therapy, and provide surgical guidance during tumor resection [13]. Recently, a first-in-human study was conducted using intra-operative tumor-specific imaging. A targeting ligand combined with a fluorophore was used for the detection of tumor-specific biomarkers for diagnostic imaging and surgical decision-making in ovarium cancer [14].

For tumor-specific imaging, a biomarker is required to function as a target. In PDAC, a large number of biomarkers are known to be overexpressed. However, a limited number of these markers are eligible candidates for targeted imaging. Potential biomarkers for tumorspecific targeting must possess certain characteristics, such as homogeneous expression, upregulation of more than ten times compared to normal and surrounding tissue, and localization on the cellular membrane [15-17]. A preliminary study from our own research group identified several potential targets which are overexpressed in pancreatic tumor compared to normal pancreatic tissues; integrin $\alpha v \beta 6$, carcinoembryonic antigen (CEA), epidermal growth factor receptor (EGFR), and urokinase plasminogen activator receptor (UPAR) [18]. These biomarkers have also shown their potential for tumor-targeted imaging in pre-clinical studies $[15,19-31]$. However, a potential target for clinically relevant differentiation between PDAC and peritumoral inflammation or CP has yet to be identified. Next to the ability to discriminate PDAC from $\mathrm{CP}$, the target also needs to be able to identify lymph node metastases and differentiate between vital tumor cells versus necrosis and fibrosis in patients that have received neoadjuvant therapy.

The primary aim of this study was to evaluate the ability of integrin $\alpha v \beta 6$, carcinoembryonic antigenrelated cell adhesion molecule 5 (CEACAM5), Cathepsin E (Cath E), EGFR, hepatocyte growth factor receptor (c-MET), thymocyte differentiation antigen 1 (Thy1), and UPAR as targets to differentiate between PDAC, CP and normal pancreatic tissue for tumor-specific imaging and for the potential to develop clinically translatable imaging agents targeting these markers. The biomarkers were selected based on a literature search and our previous study using tissue microarrays (TMA) of 137 patients [18, 19, 32, 33].

\section{RESULTS}

In the first cohort, a total of 62 tissues $(n=8$ PDAC, $\mathrm{n}=7 \mathrm{CP}, \mathrm{n}=9$ normal pancreatic tissue, $\mathrm{n}=32$ lymph nodes, $\mathrm{n}=6$ PDAC after neoadjuvant radiochemotherapy) were stained for all biomarkers to assess expression patterns. In the second cohort, a total of 55 tissue slides were stained with the two most suitable biomarkers ( $\mathrm{n}=12$ PDAC, $\mathrm{n}=12$ $\mathrm{CP}, \mathrm{n}=12$ normal pancreatic tissue, $\mathrm{n}=19$ lymph nodes). Patient and tumor characteristics are summarized in Supplementary Table 1.

\section{Avß6, CEACAM5, CathE and uPAR are significantly higher expressed in PDAC versus $\mathbf{C P}$}

All biomarkers were overexpressed in PDAC, except for c-MET (Figure 1S-1U) and Thy 1 (Figure $1 \mathrm{~J}-1 \mathrm{~L})$, which showed equal or even higher staining in normal pancreatic tissue or CP compared to PDAC. Although there was abundant Thyl stromal staining in PDAC, it was also present in stroma of adjacent normal and inflamed pancreatic tissue. Therefore, both targets were excluded from further analysis. All other targets showed significant higher expression in PDAC compared to normal pancreatic tissue; $\alpha \mathrm{v} \beta 6$ (Figure 1A1C) $(\mathrm{p}<0.001)$, CEACAM5 (Figure 1D-1F) $(\mathrm{p}<0.001)$, EGFR (Figure 1G-1I) ( $p<0.05)$, Cath E (Figure 1P$1 \mathrm{R})(\mathrm{p}<0.001)$, and uPAR (Figure $1 \mathrm{M}-1 \mathrm{O})(\mathrm{p}<0.001)$. Av $\beta 6$ was homogeneously expressed, uPAR, and Cath E were slightly heterogeneously expressed, and all other biomarkers showed a markedly heterogeneous expression pattern in PDAC tissue (Supplementary Figure 1). Furthermore, only CEACAM5 expression in PDAC was slightly more intense in the invasive border compared to the tumor core. The following biomarkers were significantly overexpressed in PDAC versus $\mathrm{CP}$; 
$\alpha v \beta 6$ (Figure 1B-1C) $(\mathrm{p}<0.001)$, CEACAM5 (Figure 1E1F) $(\mathrm{p}<0.001)$, Cath E (Figure 1Q-1R) $(\mathrm{p}<0.001)$, and uPAR (Figure 1N-1O) ( $<<0.001)$. All targets, except for CEACAM5, showed expression in the duodenum especially at the luminal side (not shown). This was also the case in colonic tissue where there was luminal staining for most targets except for uPAR (not shown).

Interestingly, immunohistochemical staining for CEACAM5 (Supplementary Figure 2) and UPAR showed complete absence of staining in normal pancreatic parenchyma. Av $\beta 6$ showed moderate staining in normal ductal structures, but there was a significantly higher expression in malignant ducti. The substantially higher ratio of ductal structures in malignant pancreatic tissue compared to normal pancreatic parenchyma adds to the significant increase of marker expression per high power field. (Supplementary Figure 3).

\section{Avß6 specifically differentiates tumor-positive and tumor-negative lymph nodes}

Next, we investigated biomarker expression in tumor-positive and -negative lymph node. A total of 17 tumor-positive and 15 tumor-negative nodes were stained. The described biomarkers identified the investigated tumor-positive and -negative lymph nodes correctly with, respectively, a sensitivity and specificity of; $\alpha \mathrm{v} \beta 6(84 \%$; 100\%), CEACAM5 (68\%; 100\%), EGFR (93\%; 67\%),

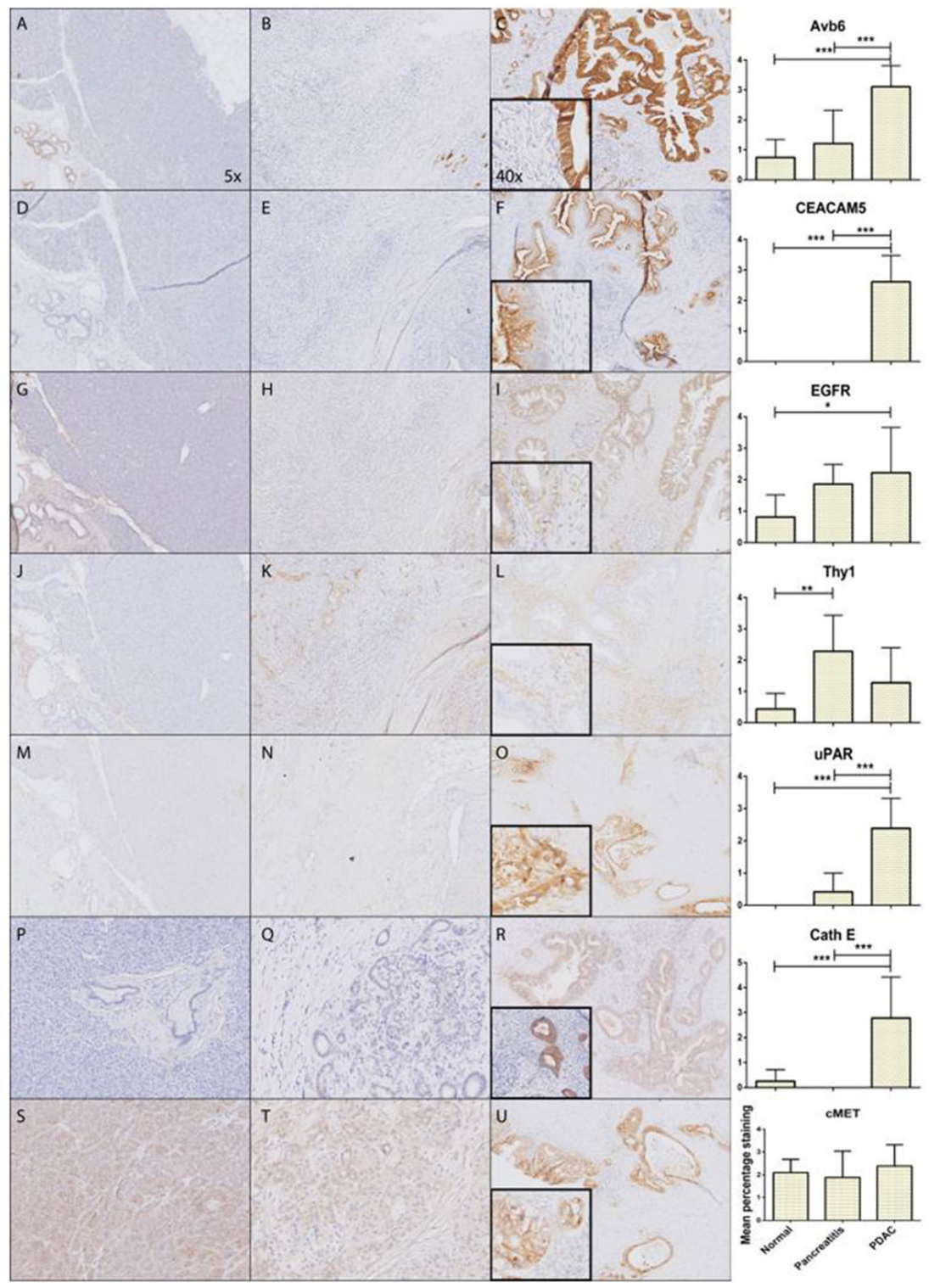

Figure 1: Expression patterns of investigated markers. Representative images of immunohistochemically staining patterns in PDAC of all molecular markers; $\alpha v \beta 6$ (A-C), CEACAM5 (D-F), EGFR (G-I), Thy1 (J-L), uPAR (M-O), CathE (P-R), cMET (S-U) showing respectively from left to right normal pancreatic tissue, CP, PDAC and graphical representation of mean percentage staining on all the tissue slides $(*: \mathrm{p}<0.05, * *: \mathrm{p}<0.01, * * *: \mathrm{p}<0.001)$. 
Cath E $(54 \% ; 83 \%)$, and uPAR $(69 \% ; 67 \%)$. Figure 2 shows biomarker expression in tumor-positive lymph nodes for all investigated biomarkers.

An interim analysis to assess the suitability of the biomarker panel as targets for tumor-specific molecular imaging of PDAC was performed, shown in Table 1. Biomarkers $\alpha v \beta 6$ and CEACAM5 met most of the criteria of an optimal tumor-specific biomarker and were selected for further evaluation.

\section{Biomarker patterns change after neoadjuvant radiochemotherapy}

Molecular targeted imaging could be useful tool for neoadjuvant therapy response monitoring. The consequence of neoadjuvant therapy on $\alpha v \beta 6$ and CEACAM5 expression was assessed by staining tissues from patients who received radiochemotherapy. In all investigated neoadjuvantly treated tumors, there was a markedly higher $\alpha v \beta 6$ expression seen in the remaining vital tumor cells compared to the surrounding fibrosis and necrosis, as shown in Figure $3 \mathrm{~A}$ and $3 \mathrm{~B}$. This level of expression was comparable to the expression in PDAC without neoadjuvant therapy, as previously shown. CEACAM5 expression in vital tumor cells after neoadjuvant therapy was reduced, as shown in Figure $3 \mathrm{C}$, compared to PDAC not treated neoadjuvantly. As a result, no difference in expression of CEACAM5 between vital tumor cells and surrounding fibrosis and necrosis was seen (Figure 3C and 3D). In the samples of two out of six patients there was no expression of CEACAM5 in the remaining vital PDAC cells. Due to small sample size, we were not able to determine significance of results.

\section{Avß6 and CEACAM5 expression is markedly different between normal pancreatic parenchyma, peritumoral inflammation, and PDAC of individual patients}

In a second cohort, normal pancreatic parenchyma, peritumoral inflammation and PDAC of individual patients $(n=12)$ were included in order to mimic the actual clinical situation. In 11 out of 12 patients, $\alpha v \beta 6$ staining in PDAC was clearly higher compared to inflammation and to normal pancreatic parenchyma (4 and 2 times higher, respectively). CEACAM5 expression was only present in PDAC, and therefore, the staining pattern was markedly different between normal pancreatic parenchyma, peritumoral inflammation and PDAC in all patients except for two who did not express CEACAM5 in any of their tissue samples (Supplementary Figure 4). In concordance with the first patient cohort, CEACAM5 staining of PDAC was weaker and more heterogeneous compared to $\alpha v \beta 6$. In Figure 4, expression of CEACAM5 (Figure 4B) and $\alpha v \beta 6$ (Figure 4C) in PDAC, peritumoral inflammation, and normal pancreatic parenchym of one individual patient are presented next to

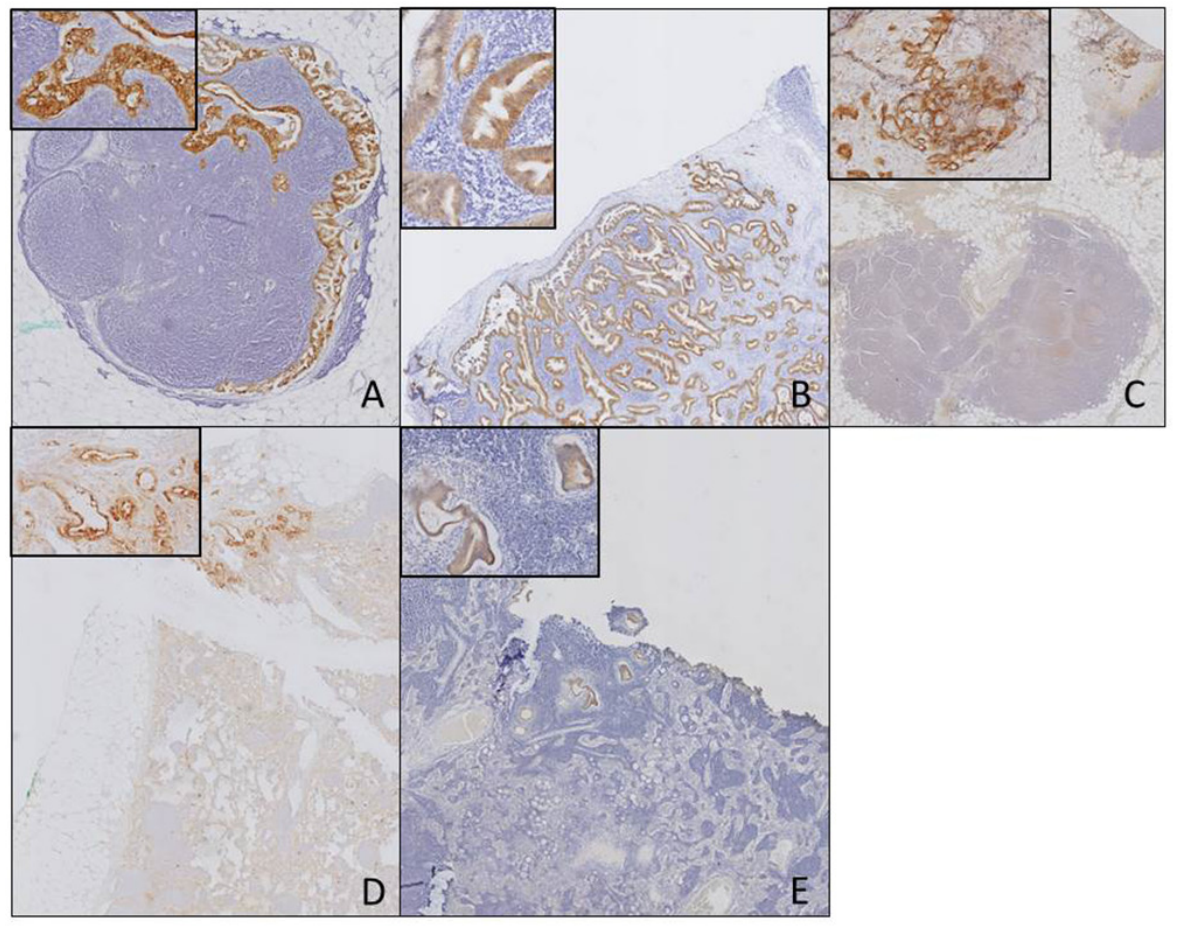

Figure 2: Biomarker expression in tumor-positive lymph nodes. Biomarker expression in tumor-positive lymph nodes for the different biomarkers $\alpha v \beta 6$ (A), CEACAM5 (B), EGFR (C), uPAR (D), CathE (E) (Objective 1x, insert 20x). 


\begin{tabular}{|c|c|c|c|c|c|c|c|}
\hline Target & Localization & $\begin{array}{l}\text { Upregulation } \\
\text { in PDAC } \\
\text { compared to } \\
\text { normal }\end{array}$ & $\begin{array}{l}\text { Upregulation } \\
\text { in PDAC } \\
\text { compared } \\
\text { to CP }\end{array}$ & $\begin{array}{c}\text { Sensitivity } \\
\text { of target } \\
\text { for lymph } \\
\text { node } \\
\text { metastases }\end{array}$ & $\begin{array}{l}\text { Diffuse } \\
\text { upregulation } \\
\text { throughout } \\
\text { the tumor }\end{array}$ & $\begin{array}{l}\text { Main } \\
\text { advantage }\end{array}$ & $\begin{array}{l}\text { Main } \\
\text { disadvantage }\end{array}$ \\
\hline$\alpha_{\mathrm{v}} \beta_{6}$ & $\begin{array}{l}\text { Cell } \\
\text { membrane }\end{array}$ & $\mathrm{p}<0.001$ & $\mathrm{p}<0.001$ & $84 \%$ & ++ & $\begin{array}{l}\text { Diffuse, strong } \\
\text { expression. }\end{array}$ & $\begin{array}{l}\text { Expression on } \\
\text { normal ductal } \\
\text { structures. }\end{array}$ \\
\hline CEACAM5 & $\begin{array}{l}\text { Cell } \\
\text { membrane }\end{array}$ & $\mathrm{p}<0.001$ & $\mathrm{p}<0.001$ & $68 \%$ & + & $\begin{array}{l}\text { No expression } \\
\text { in normal } \\
\text { pancreatic tissue } \\
\text { and CP. }\end{array}$ & $\begin{array}{l}\text { Heterogeneous } \\
\text { expression } \\
\text { and loss of } \\
\text { expression after } \\
\text { neoadjuvant } \\
\text { treatment. }\end{array}$ \\
\hline EGFR & $\begin{array}{l}\text { Cell } \\
\text { membrane }\end{array}$ & $\mathrm{p}=0.031$ & $\mathrm{p}=1.000$ & $93 \%$ & ++ & $\begin{array}{l}\text { EGFR-mediated } \\
\text { cellular } \\
\text { internalization } \\
\text { of targeted } \\
\text { particles. }\end{array}$ & $\begin{array}{l}\text { Relatively high } \\
\text { expression on } \\
\text { normal duodenal } \\
\text { tissue, thereby } \\
\text { changing } \\
\text { surgical field. }\end{array}$ \\
\hline uPAR & $\begin{array}{l}\text { Cell } \\
\text { membrane }\end{array}$ & $\mathrm{p}<0.001$ & $\mathrm{p}<0.001$ & $69 \%$ & ++ & $\begin{array}{l}\text { Expression } \\
\text { both on tumor } \\
\text { and tumor } \\
\text { surrounding } \\
\text { stromal cells. }\end{array}$ & $\begin{array}{l}\text { High uPAR } \\
\text { expression in } \\
\text { negative lymph } \\
\text { nodes. }\end{array}$ \\
\hline CathE & Intracellular & $\mathrm{p}<0.001$ & $\mathrm{p}<0.001$ & $54 \%$ & + & $\begin{array}{l}\text { Ideal for } \\
\text { imaging } \\
\text { purposes due } \\
\text { to possible use } \\
\text { of activatable } \\
\text { probes, and } \\
\text { therefore } \\
\text { increasing } \\
\text { signal-to- } \\
\text { background } \\
\text { ratio. }\end{array}$ & $\begin{array}{l}\text { Intracellular } \\
\text { location of } \\
\text { target requires a } \\
\text { probe capable of } \\
\text { internalization. }\end{array}$ \\
\hline
\end{tabular}

Overview of the characteristics of the analyzed biomarkers for determination of the suitability of the biomarker as tumortarget for molecular-imaging during pancreatic cancer surgery; Integrin $\mathrm{A}_{\mathrm{v}} \beta_{6}$, carcinoembryonic antigen (CEACAM5), epidermal growth factor receptor (EGFR), hepatocyte growth factor receptor (or c-MET), urokinase-type plasminogen activator receptor (uPAR), and Cathepsin E (Cath E). No upregulation (-). Heterogeneous upregulation in tumor (+). Diffuse expression of target $(++)$.

the corresponding H\&E stain (A), showing the difference in expression even in such close proximity.

\section{Multiplexing for optimal discrimination between malignant and benign tissue}

Double staining of CEACAM5 and $\alpha v \beta 6$ using immunofluorescence showed that multiplexing by targeting both biomarkers leads to an improved discrimination between malignant and benign pancreatic tissue and identification of all PDAC tissue. Examples of using multiplexing to achieve improved detection are shown in Figure 5, and Supplementary Figure 5. This improved detection is obtained by the different expression patterns of both targets, as also shown in Figure 1, which are complementary to each other. Targeting $\alpha v \beta 6$ will identify all PDAC as shown above, and CEACAM5 reduce the false positive staining by $\alpha v \beta 6$ in normal pancreatic parenchyma and $\mathrm{CP}$. 


\section{DISCUSSION}

Imaging using tumor-specific molecular probes has the potential to solve some of the challenges regarding PDAC diagnosis, treatment response monitoring and surgery. For tumor-specific molecular imaging to be successful, it is essential to have suitable biomarkers that can be targeted by molecular probes and are able to distinguish primary PDAC and metastases from normal pancreatic tissue, $\mathrm{CP}$ or acute (peritumoral) inflammation. With the current imaging modalities, the differentiation between PDAC and CP remains a challenge as still 7-13\%

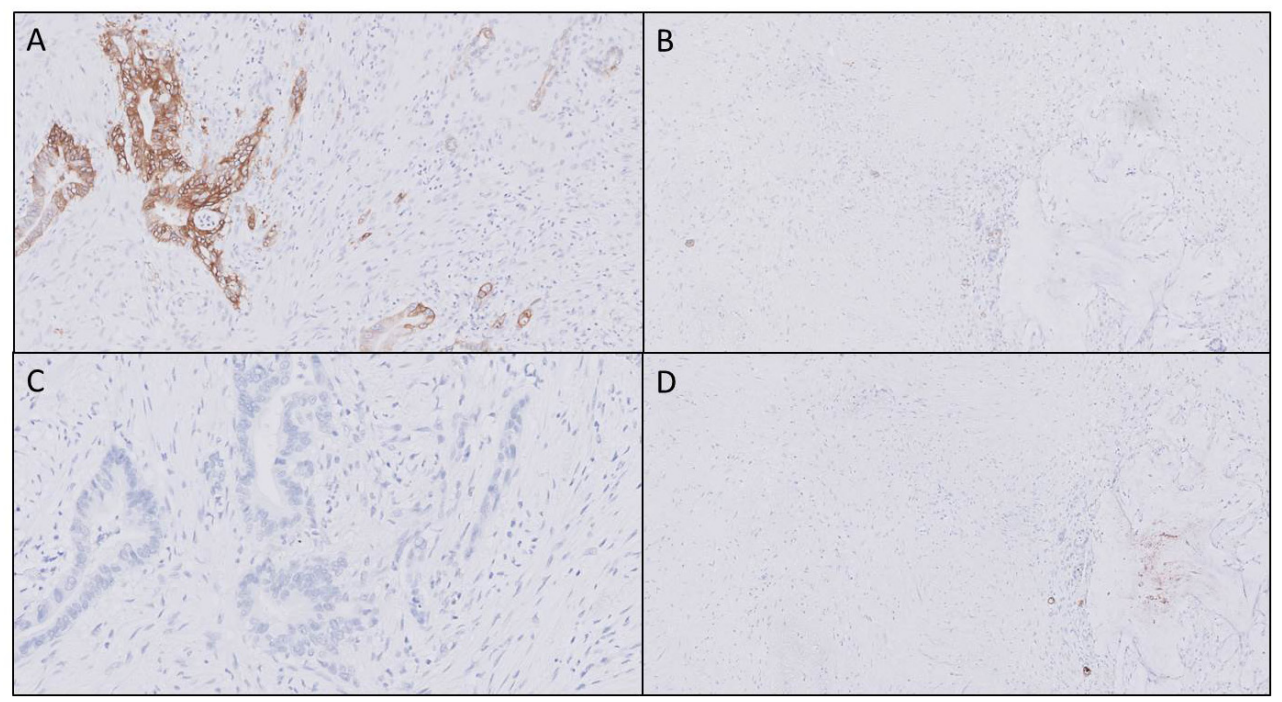

Figure 3: Biomarker expression after neoadjuvant therapy. In all neoadjuvant treated tissue a markedly higher av $\beta 6$ expression was identified in vital tumor tissue (A) compared to surrounding fibrosis or necrosis (B) after neoadjuvant therapy. CEACAM5 biomarker expression showed increased heterogeneity after neoadjuvant therapy in the tumor $(\mathbf{C})$, therefore clear distinction between vital tumor and fibrosis and necrosis is not possible (C and D) (Objective 10x)."

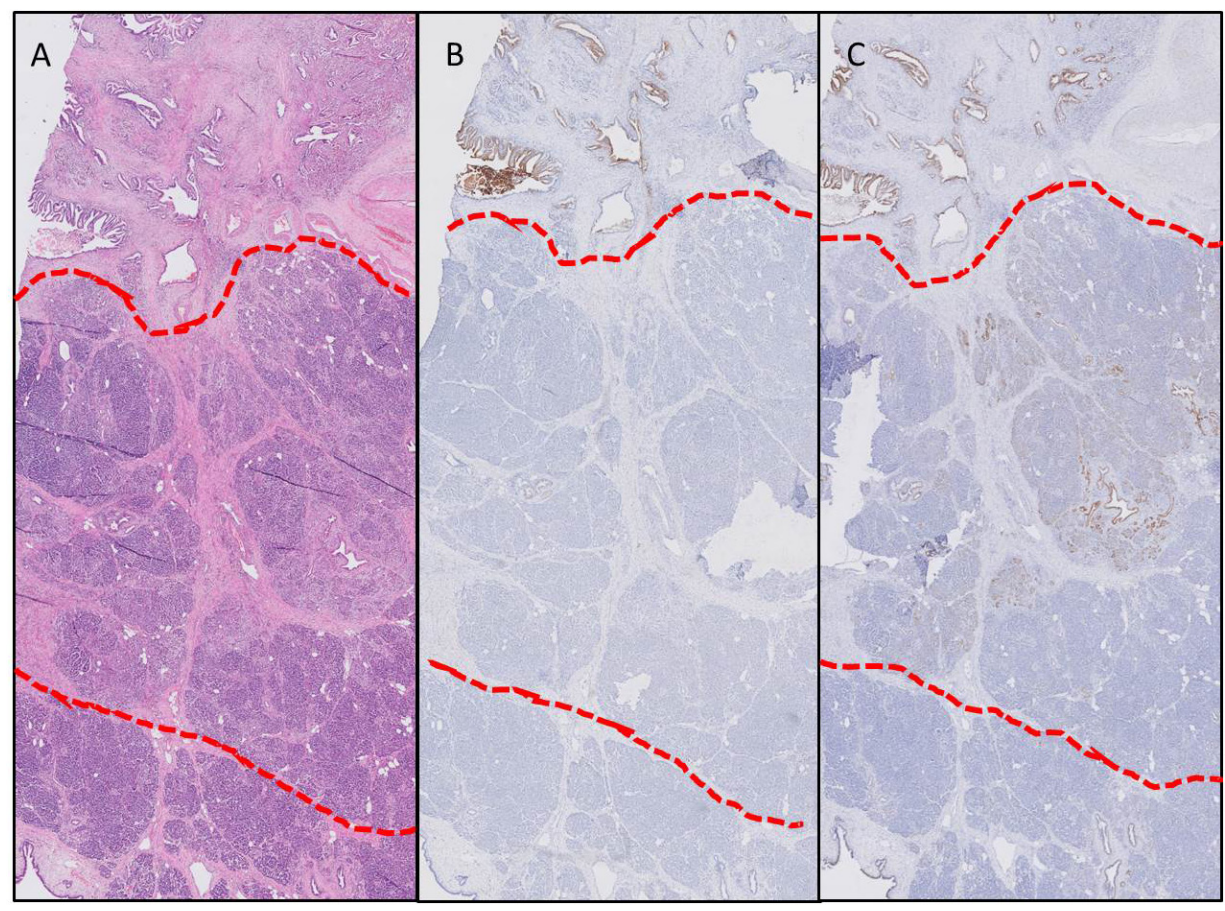

Figure 4: Biomarker expression in different tissue types within one patient. Expression of CEACAM5 (B) and $\alpha v \beta 6$ (C) of one individual patient with the corresponding H\&E slide (A) in PDAC (above red line), peritumoral inflammation (between red lines), and normal pancreatic parenchyma (below red lines), showing the difference in expression even in such a close proximity (Objective 2x)." 
of pancreatectomies are performed for benign pathology [34]. Molecular imaging can potentially also improve the outcome of PDAC patients by providing the ability to identify small tumor nodules in an early stage and therefore increasing the chance of cure and improving survival rates $[35,36]$. Another major problem for PDAC surgery is the high recurrence rate within 6-12 months, which suggests that local or distant micrometastases were already present at the time of surgery [37, 38]. This underscores that conventional imaging modalities (i.e., MRI, CT and PET) lack the sensitivity to detect small amounts of tumor leading to highly morbid surgical procedures for patients without the desired oncologic benefit. A technique that improves the stratification of patients to ensure receivement of the proper therapy could serve as a helpful tool for personalized treatment in PDAC. Examples of tumor-specific imaging modalities include: ultrasound, CT, PET, and fluorescent optical imaging. Fluorescent optical imaging has shown the ability to detect lesions $<2 \mathrm{~mm}$ as described by Warram, et al. [39]. Of course, this modality can only be used during surgery but will lead to better stratification intraoperatively.

For PDAC, the greatest improvements in patient outcome would likely be the result of better selection of patients for surgery, preoperative visualization of all tumor-positive lymph nodes and distant metastases, or the decision to abort surgery in a noncurative procedure. This study implies that molecular imaging using tumorspecific targets, such as $\alpha v \beta 6$ and CEACAM5, can help to guide this process. The main advantage of the present study is the use of tissue sections that represent a cross section of the entire pancreas which is preferred above tissue microarray (TMA) cores, as we could assess exact staining patterns more thoroughly in a larger surface and can recognize heterogeneity more reliably. This change in technique potentially explains why substantially higher expression rates are found in normal ductal pancreatic tissue compared to the literature $[18,32,40]$. To assess clinical relevance of the technique and represent the clinical situation during imaging and surgery, PDAC, lymph nodes, CP and peritumoral inflammation as well as unremarkable pancreatic parenchyma were included from the same unique patients. To our knowledge, this is the first report comparing the expression of biomarkers not only in different tissue types but also in benign and malignant lesions within the same organ from a single patient leading to the identification of ideal biomarkers for preoperative and intraoperative imaging [27, 28, 30, 41]. The results of CEACAM5 and $\alpha v \beta 6$ in PDAC tissues are in line with most previous reports [21, 27, 30, 31]. However in contrast, Allum et al. and Jewkes et al. both reported CEA staining in CP [28, 42]. For their study, they used the monoclonal anti-CEA antibodies, 11-285-14 and 11-359-6, but it is unknown if their antibodies were directed against CEACAM5 or another subtype of CEA.

The fact that CEACAM5 could be a potential biomarker for the tumor-specific identification of PDAC would lead to other advantages. CEA is known to be

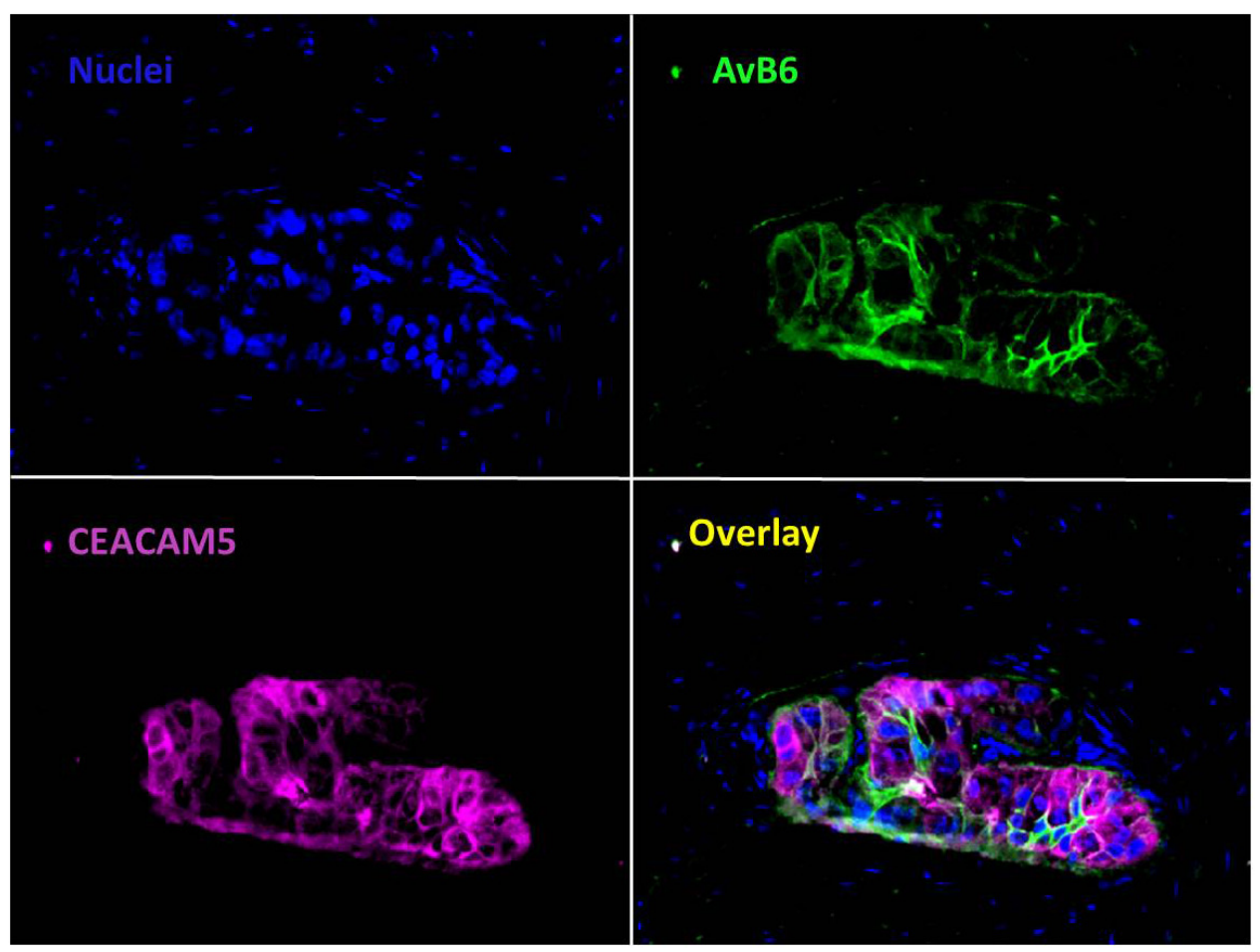

Figure 5: Value of multiplexing in PDAC. Immunofluorescent staining of $\alpha \mathrm{v} \beta 6$ and CEACAM5 simultaneously in PDAC. Showing the additional value of using two biomarkers to target all tumor tissue compared to one biomarker (Objective 40x). 
present in soluble form in the serum for multiple cancer types. Recent studies have reported a positive relation between CEA levels in cancer tissue and serum CEA levels [43, 44], while other studies did not show this relation [45-48]. For now, this phenomena is mainly studied in colorectal cancer and the correlation between serum CEA and tissue CEA in PDAC is unclear, but is subject of investigation in our group.

As shown in this study as well as in literature, no individual biomarker is perfect. For most tumor types, one unique biomarker is not sufficient for exact tumorspecific identification, and therefore the potential to perform multiplexing is crucial. In this study, we showed the advantage of using probes with different fluorescent labels for multiplexing purposes, An example of a technique which is optimal for multiplexing is Raman imaging. Several different nanoparticles can be produced by modifying the Raman surface and therefore generating unique spectral signatures [49]. Unfortunately, this technique is still far from wide clinical use. To target multiple biomarkers with fluorescence imaging, diabodies are the ligand of choice now. However, if a diabody was used with one fluorescent label to target CEACAM5 and $\alpha v \beta 6$, exact differentiation would not have been possible between normal pancreatic tissue, CP and inflammation, and PDAC since both targets have their own strengths in this differentiation. Targeting both biomarkers with different fluorescently-labeled ligands might thus be beneficial for imaging purposes.

Since the successful introduction of novel neoadjuvant regimens for PDAC, like FOLFIRINOX, resectability rates have increased up to $51 \%$ [50]. However, a major drawback of this success is that after neoadjuvant treatment conventional imaging modalities are not able to differentiate between vital tumor cells and radiochemotherapy-induced tumor necrosis and fibrosis, and are therefore no longer able to predict resectability [10]. A potential role for targeted imaging, would require that parts of the tumor that have remained vital tumor after neoadjuvant therapy would have to retained their expression levels. Av $\beta 6$ was shown to possess that capacity. CEACAM5 expression, on the other hand, was reduced compared to PDAC tissue without neoadjuvant treatment. Two potential explanations for this effect could be: (i) there is tumor heterogeneity where the subtype with CEACAM5 expression is selectively killed by the (radio) chemotherapy [51-53], or (ii) the neoadjuvant therapy has a selective effect on the cell genome [54]. However, before final conclusions can be drawn in neoadjuvant treated tissues, these results need to be validated in a larger series of patients. Another limitation of our approach in this series is that the biomarker expression before (radio)chemotherapy is unknown. However, based on the available literature and our presented results, we feel confident that biomarker expression of these tumors prior to therapy is comparable to expression in tumors that are not treated with neoadjuvant therapy.
A potential hurdle for the clinical translation of tumor-targeted imaging could be the need for agents directed against different targets in the various cancer types, which is costly and a regulatory burden. For example, the role of c-MET as a biomarker in fluorescence imaging seems to be cancer type-specific. Burggraaf et al. showed the potential of c-MET as biomarker in colon cancer [55], whereas in PDAC, its role is less clear. In this study, as with others, c-MET shows relevant overexpression in normal pancreatic tissue, excluding it as target for tumor-specific molecular imaging applications [56]. Also biomarkers targeting stromal components and microenvironment such as UPAR and Thy 1 are suggested for molecular imaging of cancer $[19,57]$. However, as shown, biomarkers targeting the microenvironment of PDAC, are less useful when extravasation occurs because abundant stroma exists not only in PDAC, but also in normal pancreatic tissue and especially in chronic and acute pancreatitis. Another main disadvantage of uPAR was the expression in negative lymph nodes, potentially due to its natural expression on macrophages. This is in line with a recently published review paper from Petrushnko et al [58]. Since lymph node identification was one of our main criteria, uPAR was not included in the second cohort for evaluation although it performed similar to CEACAM5 on several other characteristics.

In conclusion, both CEACAM5 and $\alpha v \beta 6$ are promising candidates for tumor-specific molecular imaging for PDAC. Especially when used in combination, these biomarkers can discriminate between normal pancreatic tissue, $\mathrm{CP}$ and peritumoral inflammation, and PDAC. And in addition, can identify lymph node metastases. Also, $\alpha v \beta 6$ can help identify vital tumor after neoadjuvant radiochemotherapy. Therefore, agents recognizing both biomarkers, combined with a different label or two separate agents, would have the potential to create a huge impact in PDAC diagnostics, therapy and patient outcome.

\section{MATERIALS AND METHODS}

\section{Patient and tissue selection}

Medical records and tissue specimens were retrospectively reviewed from patients who underwent pancreatic resection at the Leiden University Medical Center (LUMC) and Erasmus Medical Center (EMC) in Rotterdam between January 2011 and September 2015. Patients were selected with the histological diagnosis PDAC $(n=8)$ or $C P(n=7)$. In addition, normal pancreatic tissue lying adjacent to a PDAC was obtained from nine patients $(n=9)$. Locoregional lymph nodes $(n=32 ; n=17$ tumor-negative, $\mathrm{n}=15$ tumor-positive) were included from the PDAC patients to identify biomarker expression in lymph node metastasis. For our second cohort, all tissues $(n=55$; normal pancreatic parenchyma, inflamed pancreatic tissue, and PDAC tissue) were obtained from individual patients $(n=12)$. All tissue samples were 
reviewed by a specialized pathologist before inclusion in the study. Tumor differentiation grades according to guidelines established by the World Health Organization were included. Colonic $(n=3)$ and duodenal tissues $(n=3)$ (from Department of Pathology, LUMC) were included as controls to assess biomarker expression in the peripancreatic organs. Patterns of expression of tumor biomarkers on pancreatic surgical specimens following neoadjuvant therapy were assessed in a small cohort $(n=6)$ of patients who received radiochemotherapy; three cycles of gemcitabine and 15 fractions of 36 Gy radiotherapy during two cycles (PREOPANC trial).

\section{Antibodies and reagents}

The antibodies used for immunohistochemical (IHC) staining are shown in Supplementary Table 2.

\section{Immunohistochemistry on tissue sections}

Formalin-fixed, paraffin-embedded (FFPE) tissue blocks were collected from the Pathology Department of the LUMC and EMC. Tissue sections of $5 \mu \mathrm{m}$ thickness were obtained from two different types of tissue blocks, one type with standard measurement of $40 \times 26 \mathrm{~mm}$, and the other type of $75 \times 50 \mathrm{~mm}$. The second type was used to determine the expression pattern across the entire specimen. All tissue slides used in the study were immunohistochemically assessed. For the second cohort of slides, additional immunofluorescence was performed. For preparation of IHC staining, the slides were deparaffinized with xylene and rehydrated in serially diluted ethanol solutions ( $100 \%-50 \%)$, followed by demineralized water according to standard protocols. Endogenous peroxidase activity was blocked by incubation in $0.3 \%$ hydrogen peroxidase in phosphate buffered saline (PBS) for 20 min. Antigen retrieval for CEACAM5, Thy1, and UPAR was performed by heat induction at $95^{\circ} \mathrm{C}$ using PT Link (Dako) with low-pH Envision FLEX target retrieval solution ( $\mathrm{pH}$ 6.0, citrate buffer, Dako). For c-MET and Cath E, the high-pH Envision FLEX target retrieval solution was used ( $\mathrm{pH}$ 9.0, citrate buffer, Dako). For $\alpha v \beta 6$ and EGFR staining, antigen retrieval was performed with $0.4 \%$ pepsin incubation (Dako) at $37^{\circ} \mathrm{C}$ for $10 \mathrm{~min}$.

Following antigen retrieval, the tissue sections were incubated overnight with the primary antibodies in 100 $\mu \mathrm{l}$ for standard tissue sections and $500 \mu \mathrm{l}$ for the large tissue sections at room temperature. A pre-determined optimal dilution was used for all antibodies; anti- $\alpha v \beta 6$ antibodies 1:800, anti-CEACAM5 antibodies 1:1000, anti-EGFR antibodies 1:100, anti-CD90/Thy1 antibodies 1:800, anti-MET antibodies 1:8000, anti-Cath E antibodies 1:1000, and anti-uPAR antibodies 1:800. The slides were washed with PBS, followed by incubation with secondary antibody for 30 minutes at room temperature. After additional washing, the staining was visualized with 3,3-diaminobenzidine tetrahydrochloride solution (DAKO, Glustrup, Denmark) at room temperature for 5 minutes and counterstained with hematoxylin for 20 seconds. Finally, the tissue sections were dehydrated and mounted in Pertex (Histolab, Rockville, MD, USA).

\section{IHC analysis}

All stained sections with standard measurements (40 x $26 \mathrm{~mm}$ ) were scanned and viewed at 40x magnification using the Philips Ultra-Fast Scanner 1.6 RA (Philips, Eindhoven, Netherlands). The large tissue sections were viewed under the microscope. Evaluation of the immunohistochemical staining was performed blinded independently by two observers (W.S.F.J.T. and A.F.S.). The following scoring method was used; percentage specific staining (normal/PDAC/CP) was scored as percentage of total tissue $0=<10 \%, 1=10-25 \%, 2=26-50 \%$, $3=51-75 \%, 4=>75 \%$. Staining intensity was scored as $0=$ none, $1=$ weak, $2=$ moderate, $3=$ strong (Supplementary Figure 6). Undesired staining of structures other than investigated tissues (i.e., normal/tumor/inflammation/ stroma) was scored as $0=$ none, $1=$ moderate, $2=$ strong. In tumor tissue, a comparison was made between staining at invasive border compared to core of the tumor. This was scored as tumor core vs invasive border: $0=$ lower, $1=$ similar, $2=$ stronger.

\section{Interim analysis to assess biomarker suitability}

Primary analysis of all biomarker characteristics included expression pattern, expression in normal pancreatic parenchyma, pancreatitis, PDAC and expression in tumor-positive and tumor-negative lymph nodes. Next an interim analysis of the different biomarkers was performed to assess the suitability of these markers as targets for tumor-specific molecular imaging of PDAC. After this analysis the most suitable biomarkers ( $\alpha \mathrm{v} \beta 6$ and CEACAM5) were chosen for further assessment to specifically identify their potential in clinically relevant situations, tailored to tumor-specific molecular imaging."

\section{Immunofluorescence}

Double immunofluorescent staining of $\alpha \mathrm{v} \beta 6$ and CEACAM5 was performed on FFPE tissue sections of normal pancreatic tissue, PDAC, and CP. The slides were treated similar as described above. Antigen retrieval for both targets was performed by heat induction at $95^{\circ} \mathrm{C}$ using PT Link with a low-pH Envision FLEX target retrieval solution. Sections were incubated with 5\% Fetal Bovine Serum in PBS for 10 minutes at room temperature prior to incubation with primary antibodies. Both primary antibodies against $\alpha v \beta 6$ and CEACAM5 were applied overnight at room temperature. These were detected using secondary antibodies mentioned before; anti-IgG1-AF488 
for $\alpha v \beta 6$ and anti-IgG2a-AF647 for CEACAM5. After washing three times in PBS, nuclei were stained with 4',6-diamidino-2-phenylindole (DAPI, Prolong Gold, Life Technologies) and stored at $4^{\circ} \mathrm{C}$. The slides were examined using a Leica DM5500B digital fluorescence microscope (Leica Microsystems B.V., Son, the Netherlands) equipped with a Leica DFC365FX camera using LAS X software for image acquisition and processing.

\section{Statistical analysis}

The statistical analysis was performed using SPSS version 20.0 software for Windows (SPSS, IBM Corporation, Somer NY, USA) and GraphPad Prism 6 (GraphPad, Software, Inc, La Jolla CA, USA). Mean percentage staining and difference in staining between tissues was calculated with One-way ANOVA with post-hoc Bonferroni correction. In all tests, results were considered statistically significant at the level of $\mathrm{P}<0.05$.

\section{Abbreviations}

PDAC: pancreatic ductal adenocarcinoma; CP: chronic pancreatitis; CEACAM5: carcinoembryonic antigen-related cell adhesion molecule 5; Cath E: Cathepsin E; EGFR: epidermal growth factor receptor; c-MET: hepatocyte growth factor receptor; Thy1: thymocyte differentiation antigen 1; uPAR: urokinase-type plasminogen activator receptor; IHC: Immunohistochemistry.

\section{Author contributions}

Conception or design of the work: WST, AFS, MCB, CJV, PJK, ALV, RJS.

Data collection: WST, AFS, CHE, HAP, HM, BAB. Data analysis and interpretation: WST, AFS, MCB, RJS

Drafting the article: WST, AFS, MCB, CFS, RJS. Critical revision of the article: MCB, CFS, JSD, PJK, CJV, ALV, RJS.

Final approval of the version to be: WST, AFS, MCB, HAP, CFS, JSD, HM, CHE, published: PJK, CJV, BAB, ALV, RJS.

\section{CONFLICTS OF INTEREST}

The authors declare no conflicts of interest.

\section{FUNDING}

This work was supported by the European Research Council through an ERC Advanced Grant: project SURVive (grant 323105), and in part by Michaël-van Vloten Fonds, Lisa Waller Hayes Foundation, and Jo Kolk Studiefonds.

\section{REFERENCES}

1. Rahib L, Smith BD, Aizenberg R, Rosenzweig AB, Fleshman JM, Matrisian LM. Projecting cancer incidence and deaths to 2030: the unexpected burden of thyroid, liver, and pancreas cancers in the United States. Cancer Res. 2014; 74: 2913-21. doi: 10.1158/0008-5472.can-14-0155.

2. Vincent A, Herman J, Schulick R, Hruban RH, Goggins M. Pancreatic cancer. Lancet. 2011; 378: 607-20. doi: 10.1016/ s0140-6736(10)62307-0.

3. Stathis A, Moore MJ. Advanced pancreatic carcinoma: current treatment and future challenges. Nat Rev Clin Oncol. 2010; 7: 163-72. doi: 10.1038/nrclinonc.2009.236.

4. Barugola G, Partelli S, Marcucci S, Sartori N, Capelli P, Bassi C, Pederzoli P, Falconi M. Resectable pancreatic cancer: who really benefits from resection? Ann Surg Oncol. 2009; 16: 3316-22. doi: 10.1245/s10434-009-0670-7.

5. Parsons CM, Sutcliffe JL, Bold RJ. Preoperative evaluation of pancreatic adenocarcinoma. J Hepatobiliary Pancreat Surg. 2008; 15: 429-35. doi: 10.1007/s00534-007-1240-7.

6. Verbeke CS. Resection margins in pancreatic cancer. Surg Clin North Am. 2013; 93: 647-62. doi: 10.1016/j. suc.2013.02.008.

7. Zhang JF, Hua R, Sun YW, Liu W, Huo YM, Liu DJ, Li J. Influence of perineural invasion on survival and recurrence in patients with resected pancreatic cancer. Asian Pac J Cancer Prev. 2013; 14: 5133-9.

8. Vahrmeijer AL, Hutteman M, van der Vorst JR, van de Velde CJ, Frangioni JV. Image-guided cancer surgery using near-infrared fluorescence. Nat Rev Clin Oncol. 2013; 10: 507-18. doi: 10.1038/nrclinonc.2013.123.

9. Rosenthal EL, Warram JM, de Boer E, Chung TK, Korb ML, Brandwein-Gensler M, Strong TV, Schmalbach C, Morlandt A, Agarwal G, Hartman YE, Carroll W, Richman JS, et al. Safety and tumor-specificity of CetuximabIRDye800 for surgical navigation in head and neck cancer. Clin Cancer Res. 2015. doi: 10.1158/1078-0432. ccr-14-3284.

10. Ferrone CR, Marchegiani G, Hong TS, Ryan DP, Deshpande V, McDonnell EI, Sabbatino F, Santos DD, Allen JN, Blaszkowsky LS, Clark JW, Faris JE, Goyal L, et al. Radiological and surgical implications of neoadjuvant treatment with FOLFIRINOX for locally advanced and borderline resectable pancreatic cancer. Ann Surg. 2015; 261: 12-7. doi: 10.1097/SLA.0000000000000867.

11. Hartwig W, Werner J, Jager D, Debus J, Buchler MW. Improvement of surgical results for pancreatic cancer. Lancet Oncol. 2013; 14: e476-85. doi: 10.1016/ s1470-2045(13)70172-4.

12. Sahani DV, Bonaffini PA, Catalano OA, Guimaraes AR, Blake MA. State-of-the-art PET/CT of the pancreas: current role and emerging indications. Radiographics. 2012; 32: 1133-58; discussion 58-60. doi: 10.1148/rg.324115143. 
13. Streeter JE, Herrera-Loeza SG, Neel NF, Yeh JJ, Dayton PA. A comparative evaluation of ultrasound molecular imaging, perfusion imaging, and volume measurements in evaluating response to therapy in patient-derived xenografts. Technol Cancer Res Treat. 2013; 12: 311-21.

14. van Dam GM, Themelis G, Crane LM, Harlaar NJ, Pleijhuis RG, Kelder W, Sarantopoulos A, de Jong JS, Arts HJ, van der Zee AG, Bart J, Low PS, Ntziachristos V. Intraoperative tumor-specific fluorescence imaging in ovarian cancer by folate receptor-alpha targeting: first in-human results. Nat Med. 2011; 17: 1315-9. doi: 10.1038/nm.2472.

15. Harsha HC, Kandasamy K, Ranganathan P, Rani S, Ramabadran S, Gollapudi S, Balakrishnan L, Dwivedi SB, Telikicherla D, Selvan LD, Goel R, Mathivanan S, Marimuthu A, et al. A compendium of potential biomarkers of pancreatic cancer. PLoS Med. 2009; 6: e1000046. doi: 10.1371/journal.pmed.1000046.

16. Sega EI, Low PS. Tumor detection using folate receptortargeted imaging agents. Cancer Metastasis Rev. 2008; 27: 655-64. doi: 10.1007/s10555-008-9155-6.

17. van Oosten M, Crane LM, Bart J, van Leeuwen FW, van Dam GM. Selecting potential targetable biomarkers for imaging purposes in colorectal cancer using TArget Selection Criteria (TASC): a novel target identification tool. Transl Oncol. 2011; 4: 71-82.

18. de Geus SW, Boogerd LS, Swijnenburg RJ, Mieog JS, Tummers WS, Prevoo HA, Sier CF, Morreau H, Bonsing BA, van de Velde CJ, Vahrmeijer AL, Kuppen PJ. Selecting tumor-specific molecular targets in pancreatic adenocarcinoma: paving the way for image-guided pancreatic surgery. Mol Imaging Biol. 2016. doi: 10.1007/ s11307-016-0959-4.

19. Foygel K, Wang H, Machtaler S, Lutz AM, Chen R, Pysz M, Lowe AW, Tian L, Carrigan T, Brentnall TA, Willmann JK. Detection of pancreatic ductal adenocarcinoma in mice by ultrasound imaging of thymocyte differentiation antigen 1. Gastroenterology. 2013; 145: 885-94. doi: 10.1053/j. gastro.2013.06.011.

20. Boonstra MC, van Driel PB, van Willigen DM, Stammes MA, Prevoo HA, Tummers QR, Mazar AP, Beekman FJ, Kuppen PJ, van de Velde CJ, Lowik CW, Frangioni JV, van Leeuwen FW, et al. uPAR-targeted multimodal tracer for preand intraoperative imaging in cancer surgery. Oncotarget. 2015; 6: 14260-73. doi: 10.18632/oncotarget.3680.

21. Boonstra MC, Tolner B, Schaafsma BE, Boogerd LS, Prevoo HA, Bhavsar G, Kuppen PJ, Sier CF, Bonsing BA, Frangioni JV, van de Velde CJ, Chester KA, Vahrmeijer AL. Pre-clinical evaluation of a novel CEA-targeting near-infrared fluorescent tracer delineating colorectal and pancreatic tumors. Int J Cancer. 2015; 137: 1910-20. doi: 10.1002/ijc.29571.

22. Kimura RH, Teed R, Hackel BJ, Pysz MA, Chuang CZ, Sathirachinda A, Willmann JK, Gambhir SS. Pharmacokinetically stabilized cystine knot peptides that bind alpha-v-beta- 6 integrin with single-digit nanomolar affinities for detection of pancreatic cancer. Clin Cancer Res. 2012; 18: 839-49. doi: 10.1158/1078-0432. CCR-11-1116.

23. Hildenbrand R, Niedergethmann M, Marx A, Belharazem D, Allgayer H, Schleger C, Strobel P. Amplification of the urokinase-type plasminogen activator receptor (uPAR) gene in ductal pancreatic carcinomas identifies a clinically highrisk group. Am J Pathol. 2009; 174: 2246-53. doi: 10.2353/ ajpath.2009.080785.

24. Hackel BJ, Kimura RH, Miao Z, Liu H, Sathirachinda A, Cheng Z, Chin FT, Gambhir SS. 18F-fluorobenzoatelabeled cystine knot peptides for PET imaging of integrin alphavbeta6. J Nucl Med. 2013; 54: 1101-5. doi: 10.2967/ jnumed.112.110759.

25. Metildi CA, Kaushal S, Luiken GA, Hoffman RM, Bouvet M. Advantages of fluorescence-guided laparoscopic surgery of pancreatic cancer labeled with fluorescent anticarcinoembryonic antigen antibodies in an orthotopic mouse model. J Am Coll Surg. 2014; 219: 132-41. doi: 10.1016/j.jamcollsurg.2014.02.021.

26. Paudyal B, Paudyal P, Shah D, Tominaga H, Tsushima Y, Endo K. Detection of vascular endothelial growth factor in colon cancer xenografts using bevacizumab based near infrared fluorophore conjugate. J Biomed Sci. 2014; 21: 35. doi: 10.1186/1423-0127-21-35.

27. Sipos B, Hahn D, Carceller A, Piulats J, Hedderich J, Kalthoff H, Goodman SL, Kosmahl M, Kloppel G. Immunohistochemical screening for beta6-integrin subunit expression in adenocarcinomas using a novel monoclonal antibody reveals strong up-regulation in pancreatic ductal adenocarcinomas in vivo and in vitro. Histopathology. 2004; 45: 226-36. doi: 10.1111/j.1365-2559.2004.01919.x.

28. Allum WH, Stokes HJ, Macdonald F, Fielding JW. Demonstration of carcinoembryonic antigen (CEA) expression in normal, chronically inflamed, and malignant pancreatic tissue by immunohistochemistry. J Clin Pathol. 1986; 39: 610-4.

29. Handra-Luca A, Hammel P, Sauvanet A, Lesty C, Ruszniewski P, Couvelard A. EGFR expression in pancreatic adenocarcinoma. Relationship to tumour morphology and cell adhesion proteins. J Clin Pathol. 2014; 67: 295-300. doi: 10.1136/jclinpath-2013-201662.

30. Gebauer F, Wicklein D, Horst J, Sundermann P, Maar H, Streichert T, Tachezy M, Izbicki JR, Bockhorn M, Schumacher U. Carcinoembryonic antigen-related cell adhesion molecules (CEACAM) 1, 5 and 6 as biomarkers in pancreatic cancer. PLoS One. 2014; 9: e113023. doi: 10.1371/journal.pone.0113023.

31. Hammarstrom S. The carcinoembryonic antigen (CEA) family: structures, suggested functions and expression in normal and malignant tissues. Semin Cancer Biol. 1999; 9: 67-81. doi: 10.1006/scbi.1998.0119.

32. Zhu J, Thakolwiboon S, Liu X, Zhang M, Lubman DM. Overexpression of CD90 (Thy-1) in pancreatic 
adenocarcinoma present in the tumor microenvironment. PLoS One. 2014; 9: e115507. doi: 10.1371/journal. pone. 0115507.

33. Cruz-Monserrate Z, Abd-Elgaliel WR, Grote T, Deng D, Ji B, Arumugam T, Wang H, Tung CH, Logsdon CD. Detection of pancreatic cancer tumours and precursor lesions by cathepsin E activity in mouse models. Gut. 2012; 61: 1315-22. doi: 10.1136/gutjnl-2011-300544.

34. Gerritsen A, Molenaar IQ, Bollen TL, Nio CY, Dijkgraaf MG, van Santvoort HC, Offerhaus GJ, Brosens LA, Biermann K, Sieders E, de Jong KP, van Dam RM, van der Harst E, et al. Preoperative characteristics of patients with presumed pancreatic cancer but ultimately benign disease: a multicenter series of 344 pancreatoduodenectomies. Ann Surg Oncol. 2014; 21: 3999-4006. doi: 10.1245/ s10434-014-3810-7.

35. Tummala $\mathrm{P}$, Junaidi $\mathrm{O}$, Agarwal B. Imaging of pancreatic cancer: an overview. J Gastrointest Oncol. 2011; 2: 168-74. doi: 10.3978/j.issn.2078-6891.2011.036.

36. Agarwal B, Correa AM, Ho L. Survival in pancreatic carcinoma based on tumor size. Pancreas. 2008; 36: e1520. doi: 10.1097/mpa.0b013e31814de421.

37. Fischer R, Breidert M, Keck T, Makowiec F, Lohrmann C, Harder J. Early recurrence of pancreatic cancer after resection and during adjuvant chemotherapy. Saudi J Gastroenterol. 2012; 18: 118-21. doi: 10.4103/1319-3767.93815.

38. Shimada K, Sakamoto Y, Sano T, Kosuge T. The role of paraaortic lymph node involvement on early recurrence and survival after macroscopic curative resection with extended lymphadenectomy for pancreatic carcinoma. J Am Coll Surg. 2006; 203: 345-52. doi: 10.1016/j. jamcollsurg.2006.05.289.

39. Warram JM, de Boer E, Moore LS, Schmalbach CE, Withrow KP, Carroll WR, Richman JS, Morlandt AB, Brandwein-Gensler M, Rosenthal EL. A ratiometric threshold for determining presence of cancer during fluorescence-guided surgery. J Surg Oncol. 2015; 112: 2-8. doi: 10.1002/jso.23946.

40. Hausner SH, Abbey CK, Bold RJ, Gagnon MK, Marik J, Marshall JF, Stanecki CE, Sutcliffe JL. Targeted in vivo imaging of integrin alphavbeta6 with an improved radiotracer and its relevance in a pancreatic tumor model. Cancer Res. 2009; 69: 5843-50.

41. Park SJ, Gu MJ, Lee DS, Yun SS, Kim HJ, Choi JH. EGFR expression in pancreatic intraepithelial neoplasia and ductal adenocarcinoma. Int J Clin Exp Pathol. 2015; 8: 8298-304.

42. Jewkes AJ, Macdonald F, Downing R, Drolc Z, Allum WH. Labelled antibody imaging in pancreatic cancer, cholangiocarcinoma, chronic pancreatitis and sclerosing cholangitis. Eur J Surg Oncol. 1991; 17: 354-7.

43. Park JW, Chang HJ, Kim BC, Yeo HY, Kim DY. Clinical validity of tissue carcinoembryonic antigen expression as ancillary to serum carcinoembryonic antigen concentration in patients curatively resected for colorectal cancer. Colorectal Dis. 2013; 15: e503-11. doi: 10.1111/codi.12304.

44. Saito G, Sadahiro S, Okada K, Tanaka A, Suzuki T, Kamijo A. Relation between carcinoembryonic antigen levels in colon cancer tissue and serum carcinoembryonic antigen levels at initial surgery and recurrence. Oncology. 2016; 91: 85-9. doi: 10.1159/000447062.

45. Khoo SK, Warner NL, Lie JT, Mackay IR. Carcinoembryonic antigenic activity of tissue extracts: a quantitative study of malignant and benign neoplasms, cirrhotic liver, normal adult and fetal organs. Int J Cancer. 1973; 11: 681-7.

46. Cosimelli M, De Peppo F, Castelli M, Giannarelli D, Schinaia G, Castaldo P, Buttini GL, Sciarretta F, Bigotti G, Di Filippo F, Cavaliere F, Cavaliere R. Multivariate analysis of a tissue CEA, TPA, and CA 19.9 quantitative study in colorectal cancer patients. A preliminary finding. Dis Colon Rectum. 1989; 32: 389-97.

47. Nakagoe T, Sawai T, Ayabe H, Nakazaki T, Ishikaw H, Hatano K, Kajiwara K, Miyashita K, Matsuo T, Nogawa T, Arisawa K. Prognostic value of carcinoembryonic antigen (CEA) in tumor tissue of patients with colorectal cancer. Anticancer Res. 2001; 21: 3031-6.

48. Nazato DM, Matos LL, Waisberg DR, Souza JR, Martins LC, Waisberg J. Prognostic value of carcinoembryonic antigen distribution in tumor tissue of colorectal carcinoma. Arq Gastroenterol. 2009; 46: 26-31.

49. Zavaleta CL, Kircher MF, Gambhir SS. Raman's "effect" on molecular imaging. J Nucl Med. 2011; 52: 1839-44. doi: 10.2967/jnumed.111.087775.

50. Blazer M, Wu C, Goldberg RM, Phillips G, Schmidt C, Muscarella P, Wuthrick E, Williams TM, Reardon J, Ellison EC, Bloomston M, Bekaii-Saab T. Neoadjuvant modified (m) FOLFIRINOX for locally advanced unresectable (LAPC) and borderline resectable (BRPC) adenocarcinoma of the pancreas. Ann Surg Oncol. 2015; 22: 1153-9. doi: 10.1245/s10434-014-4225-1.

51. Sahoo S, Lester SC. Pathology of breast carcinomas after neoadjuvant chemotherapy: an overview with recommendations on specimen processing and reporting. Arch Pathol Lab Med. 2009; 133: 633-42. doi: 10.1043/1543-2165-133.4.633.

52. Bracci L, Schiavoni G, Sistigu A, Belardelli F. Immunebased mechanisms of cytotoxic chemotherapy: implications for the design of novel and rationale-based combined treatments against cancer. Cell Death Differ. 2014; 21: 15-25. doi: 10.1038/cdd.2013.67.

53. Letai A. Cell death and cancer therapy: don't forget to kill the cancer cell! Clin Cancer Res. 2015; 21: 5015-20. doi: 10.1158/1078-0432.ccr-15-1204.

54. Merlo LM, Pepper JW, Reid BJ, Maley CC. Cancer as an evolutionary and ecological process. Nat Rev Cancer. 2006; 6: 924-35. doi: 10.1038/nrc2013. 
55. Burggraaf J, Kamerling IM, Gordon PB, Schrier L, de Kam ML, Kales AJ, Bendiksen R, Indrevoll B, Bjerke RM, Moestue SA, Yazdanfar S, Langers AM, Swaerd-Nordmo $\mathrm{M}$, et al. Detection of colorectal polyps in humans using an intravenously administered fluorescent peptide targeted against c-Met. Nat Med. 2015; 21: 955-61. doi: 10.1038/ nm.3641.

56. Kiehne K, Herzig KH, Folsch UR. c-met expression in pancreatic cancer and effects of hepatocyte growth factor on pancreatic cancer cell growth. Pancreas. 1997; 15: 35-40.
57. Boonstra MC, Prakash J, Van De Velde CJ, Mesker WE, Kuppen PJ, Vahrmeijer AL, Sier CF. Stromal targets for fluorescent-guided oncologic surgery. Front Oncol. 2015; 5: 254. doi: 10.3389/fonc.2015.00254.

58. Petrushnko W, Gundara JS, De Reuver PR, O'Grady G, Samra JS, Mittal A. Systematic review of peri-operative prognostic biomarkers in pancreatic ductal adenocarcinoma. HPB (Oxford). 2016; 18: 652-63. doi: 10.1016/j. hpb.2016.05.004. 